\title{
Over-the-Counter Analgesic Use Patterns in Appalachian Older Adults, Focusing on Non-Steroidal Anti-Inflammatory Drugs
}

Courtney D. Wellman, MD'1, Jordan Ratcliffe, BS ${ }^{1}$, William Rollyson, MD', Adam M. Franks, MD' ${ }^{1}$, Mike Grome, PA-C ${ }^{1}$, Robert Walker, MD ${ }^{1}$

ABSTRACT

INTRODUCTION: Elderly patients commonly use over-the-counter (OTC) medications to self-manage pain symptoms. Medications such as non-steroidal anti-inflammatory drugs (NSAIDs), acetaminophen, and topical analgesics are readily available and may seem harmless to patients. In the growing population of those 65 years and older, providers need to inquire about OTC medication use due to the increased risk for adverse reactions in this population. Complications related to these medications can be worsened by chronic disease, variable metabolism, and polypharmacy, which become more common in older adults.
Author affiliations are listed at the end of this article.

Correspondence to: Courtney Wellman, MD Marshall Unviersity Joan C. Edwards School of Medicine walkerr@marshall.edu

Methods: A survey was created to determine the prevalence and habits of OTC use in the central Appalachian population, and the potential harms related to provider awareness, chronic disease, and polypharmacy.

Results: Of surveyed Appalachian seniors ( $n=307), 86.3 \%$ take OTC medications. Of these, $57.4 \%$ report that they do not tell their provider, and $51.3 \%$ do not take the medication as directed. Within this population, $19.2 \%$ of those on blood thinners, $22.4 \%$ of those with hypertension, $34.8 \%$ of those with chronic kidney disease, and $30.6 \%$ of those with gastrointestinal issues not only use NSAIDs but do not inform their physician nor follow the packaging instructions.

DISCUSSION: Potential complications of NSAID use related to these medical comorbidities are well known. Providers need to regularly ask their older adult patients about the use of OTC medication to prevent adverse events in this vulnerable population.

\section{KEYWORDS}

Older Adults, Analgesics, NSAID, Appalachian

\section{INTRODUCTION}

According to 2012 National Projections, 20\% of the population of the United States (US) is projected to be 65 years and older in 2050. ${ }^{1}$ This compares to 13\% in 2010 and 9.8\% in 1970. ${ }^{1}$ West Virginia (WV) is expected to exceed this rate with a projection of $22.9 \%$ of the population over age 65 in $2030 .^{2}$ As this population becomes more extensive, it is crucial for primary care providers across WV and the US to identify risks impacting older patients. This includes the risk of over-the-counter (OTC) medications such as non-steroidal anti-inflammatory drugs (NSAIDs), acetaminophen, and topical analgesics.

NSAIDs are of particular importance due to their side effect profile and availability. The most common side effect of NSAID use is gastrointestinal symptoms such as dyspepsia, heartburn, and nausea; however, those over age 60 have a greater risk of developing these mild side effects and more severe side effects such as ulcers..$^{3-7}$ Another concerning effect involves renal function. Kidney injury is often dose/durationdependent and reversible; however, the causes of 
chronic renal failure related to NSAID use (interstitial nephritis or papillary necrosis) occur more commonly in the older adult population. ${ }^{3,46}$ Poor outcomes associated with renal injury are increased by the prevalence of baseline chronic kidney disease (CKD) in the older adult population due to the natural decline in glomerular filtration rate with age. Lastly, NSAIDs act as an inhibitor of platelet aggregation, leading to increased bleeding risk. This is especially important with aspirin use as it irreversibly binds to the cyclooxygenase enzyme and inactivates platelet aggregation for the lifetime of the platelet (eight to 12 days). ${ }^{7}$

Acetaminophen use in the older population is also of interest. The American Geriatric Society recommends using acetaminophen as a first-line treatment for mild to moderate chronic pain in the elderly. ${ }^{9,10}$ While acetaminophen toxicity is dose-related, its use in combination with many other OTC formulations may result in over-dosage ( $>4$ grams per day). ${ }^{6,11}$ Acetaminophen is one of the most common causes of drug-induced liver injury and accounts for $20 \%$ of liver transplants in the US. ${ }^{12}$ Patient education about acetaminophen use is beneficial in all age groups but especially in the older adult population due to their variable metabolism of the drug. ${ }^{6}$

According to the National Health Interview Survey of 2016, the prevalence of chronic pain in those 65-84 years of age was $27.6 \%$ and was $33.6 \%$ in those 85 years and older. ${ }^{13}$ These patients commonly turn to OTC analgesics for relief. In a study performed by Barat, Andreason, and Damsgaard in 2000, it was estimated that $72 \%$ of community-dwelling elders 75-years and older used OTC medications. ${ }^{14}$ Another study conducted on older individuals in a rural community reported that $87 \%$ used at least one OTC medication, and $5.7 \%$ took more than five OTC medications. ${ }^{15}$ Healthcare providers need to be aware of the type and extent of their use to anticipate and prevent side effects and drug interactions in this vulnerable population. ${ }^{16,17}$ The purpose of this study was to estimate the use of OTC analgesics, the communication to the primary care provider, and the comorbid risk factors of an older Appalachian population.

\section{METHODS}

To assess the non-prescription pain medication habits of older adults (65+ years old), project staff created and administered a short survey to a nonrandomized sample of consecutively encountered residents of Kentucky, Ohio, and West Virginia at the 2019 Cabell Huntington Hospital Senior Fair, the Center for Healthy Aging, and Marshall Health offices in Barboursville, Lavalette, and Huntington, West Virginia. It included demographic questions about gender, age, and county of residence, and binary yes/no habit questions including notification of provider, use per labeled instructions, use of blood thinners, use of hypertensive medications, presence of kidney disease, and presence of GI disorders. Fellowship-trained geriatricians and research staff created the survey and piloted it with a small group of older adults for understanding and accuracy. Over $96 \%$ of the questions that were verifiable within the electronic health record were found accurate.

Statistical analyses were performed using SAS9.4. A binary logistic regression model was built with the targeted variable:"whether the physician was aware of the patient's analgesic use." Predictor variables were age, gender, residing county, adherence to the drug label, blood thinner use, blood pressure medication use, presence of kidney disease, presence of GI pathology, and type of OTC analgesic used. Except for the continuous variable age, all other variables were treated as categorical variables. The effects significantly associated with the target variable $(p<0.05)$ were identified, and the odds ratio and their Wald confidence intervals were reported. The ROC curve evaluated the performance of the model. This project was approved by Marshall IRB (\#1177330-6).

\section{RESULTS}

Table 1 details the demographics of the 307 surveyed patients, broken down into specific groups for OTC analgesic used and combined into NSAID, non-NSAID, and no analgesic used groupings. When combined by Cabell, Lincoln, and other counties, 
Demographics of Studied Appalachain Seniors

\begin{tabular}{|c|c|c|c|c|c|c|c|c|c|c|c|c|c|}
\hline \multirow{3}{*}{ Number } & & Total & Acetaminoplen & Aspinin & Herbal & Ibuprofen & Naprosyn & Topical & None & $\mathrm{NSAD}_{\mathrm{s}}$ & Not NSAD & & \\
\hline & & 307 & 119 & 17 & 5 & 72 & 41 & 11 & \multirow{2}{*}{$\begin{array}{c}42 \\
13.68 \%\end{array}$} & \multirow{2}{*}{$\begin{array}{c}130 \\
42.35 \% \\
\end{array}$} & \multirow{2}{*}{\begin{tabular}{|c|}
135 \\
$43.97 \%$ \\
\end{tabular}} & & \\
\hline & & & $38.26 \%$ & $5.47 \%$ & $1.61 \%$ & $23.15 \%$ & $13.18 \%$ & $3.54 \%$ & & & & $\mathrm{ChiSq}$ & P Value \\
\hline \multicolumn{2}{|c|}{ Age (yrs) } & 79.7 & 77.2 & 81.9 & 74.0 & 75.7 & 77.8 & 78.9 & 80.5 & 79.3 & 79.7 & $0.6888^{\wedge}$ & 0.4066 \\
\hline \multirow[t]{3}{*}{ Geader } & Female & 178 & 81 & 8 & 4 & 37 & 27 & 9 & 12 & 72 & 94 & \multirow[b]{3}{*}{$22.7891^{*}$} & \\
\hline & \multirow[t]{2}{*}{ Male } & 129 & 38 & 9 & 1 & 35 & 14 & 2 & 30 & 58 & 41 & & \\
\hline & & $57.98 \%$ & $68.07 \%$ & $47.06 \%$ & $80.00 \%$ & $51.39 \%$ & $65.85 \%$ & $81.82 \%$ & $28.57 \%$ & $55.38 \%$ & $69.63 \%$ & & \\
\hline \multirow[t]{11}{*}{ County } & \multirow{5}{*}{\begin{tabular}{l|} 
Carter, KY \\
Lawreace, KY \\
Chesapeake, OH \\
Boone, WV \\
Cabell, WV
\end{tabular}} & 2 & 0 & 0 & 0 & 2 & 0 & 0 & 0 & 2 & 0 & \multirow[b]{11}{*}{$5.062^{*}$} & \multirow[b]{11}{*}{0.280994} \\
\hline & & 3 & 3 & 0 & 0 & 0 & 0 & 0 & 0 & 0 & 3 & & \\
\hline & & 1 & 0 & 0 & 0 & 0 & 1 & 0 & 0 & 1 & 0 & & \\
\hline & & 3 & 0 & 0 & 0 & 2 & 1 & 0 & 0 & 3 & 0 & & \\
\hline & & 124 & 49 & 3 & 2 & 24 & 17 & 6 & 21 & 46 & 57 & & \\
\hline & \multirow{6}{*}{$\begin{array}{l}\text { Kranawh, wV } \\
\text { Lincoln, WV } \\
\text { Mason, WV } \\
\text { Putnam, WV } \\
\text { Wayse, WV } \\
\text { Wyoming, WV }\end{array}$} & 4 & 3 & 0 & 1 & 0 & 0 & 0 & 0 & 0 & 4 & & \\
\hline & & 143 & 54 & 9 & 2 & 39 & 21 & 2 & 15 & 70 & 58 & & \\
\hline & & 4 & 1 & 2 & 0 & 0 & 0 & 0 & 1 & 2 & 1 & & \\
\hline & & 8 & 2 & 1 & 0 & 1 & 0 & 0 & 4 & 2 & 2 & & \\
\hline & & 18 & 7 & 2 & 0 & 3 & 1 & 3 & 1 & 6 & 11 & & \\
\hline & & 1 & 0 & 0 & 0 & 1 & 0 & 0 & 0 & 1 & 0 & & \\
\hline
\end{tabular}

TABLE 1: Demographics of the 307 senior patients surveyed is the numerator on the top.

* calculated by simple T-Table Test.

$\wedge$ calculated by logistic regression.

combined groupings are similar for age (chi-square $0.6888 ; p$-value 0.4066 ) and county (chi-square 5.062; $p$-value 0.2810). Differences were seen for gender (chi-square 22.7891; p-value 0.000011), with women most likely to use OTC analgesia, specifically non-NSAIDs, and least likely to reply "none" to the OTC analgesic question.

Groupings of no medications, NSAIDs, and no NSAIDs differed only in following the prescribing label (chi-square 64.6961; p-value $<0.00001$ ). There were no differences in comorbidities between the groups (Table 2).

Independent factors affecting the likelihood of the patient informing their physician about their OTC analgesic use are located in Figure 1. Independent factors associated with an increased chance of disclosing the medication included following the labeled instructions ( $\mathrm{OR}=0.195, \mathrm{Cl}=0.094-0.406)$ and anticoagulant use $(\mathrm{OR}=0.420, \mathrm{Cl}=0.212-0.824)$. Variables associated with a decreased chance of disclosing OTC analgesic use to their provider are living outside Cabell County $(\mathrm{OR}=2.006 ; \mathrm{Cl}=1.130$ 3.560), having $\mathrm{Gl}$ pathology $(\mathrm{OR}=2.103 ; \mathrm{Cl}=1.166-$ 3.794), and use of acetaminophen ( $\mathrm{OR}=2.229 ; \mathrm{Cl}=$
1.251-3.973). The ROC curve was scored as 0.7573 .

When the data set for OTC NSAID use was analyzed, negative answers for both the "informing the physician" and "following the label" questions revealed that a startling number of patients with vulnerable comorbidities used unknown amounts of NSAIDs without their physician's knowledge. This was true for patients on blood thinners, with hypertension, with kidney disease, and with Gl pathology at levels of $19.2 \%, 22.4 \%, 34.8 \%$, and $30.6 \%$, respectively.

\section{DISCUSSION}

NSAIDs, acetaminophen, and herbal or topical analgesics are commonly used OTC medications. ${ }^{12,13}$ Due to chronic medical problems that require multiple medications, the elderly population is more vulnerable to the dangers of OTC analgesic use. Knowledge of this use in an older Appalachian adult population provides beneficial information for practice improvement. A large population of older adults in central Appalachia was surveyed regarding their use of OTC analgesics and comorbid conditions 


\begin{tabular}{|c|c|c|c|c|c|c|c|c|c|c|c|c|}
\hline & Total & Asctaminoplet & Aspoin & Herbal & Dwagerofen & Napeosy & Topical & None & NSAIDs & Jot NSAII & $\mathrm{ChiSq}$ & P Value \\
\hline \multicolumn{13}{|l|}{ Does Doc Krow } \\
\hline No & 152 & 77 & 9 & 1 & 39 & 21 & 5 & $\mathrm{~N} / \mathrm{A}$ & 68 & 83 & \multirow[b]{2}{*}{$2.2737 \mathrm{k}$} & \multirow[b]{2}{*}{0.131583} \\
\hline Yes & 113 & 42 & 8 & 4 & 33 & 20 & 6 & $\mathrm{~N} / \mathrm{A}$ & 62 & 52 & & \\
\hline \multicolumn{13}{|l|}{ Take as Dirested } \\
\hline No & 136 & 96 & 7 & 1 & 17 & 10 & 5 & $\mathrm{~N} / \mathrm{A}$ & 34 & 102 & \multirow[b]{2}{*}{$64.6961^{\circ}$} & \multirow[b]{2}{*}{$<0.00001$} \\
\hline Yes & 129 & 23 & 10 & 4 & 55 & 31 & 6 & $\mathrm{~N} / \mathrm{A}$ & 96 & 33 & & \\
\hline \multicolumn{13}{|c|}{ On Blood Thimer } \\
\hline No & 240 & 89 & 11 & 3 & 58 & 35 & 9 & 35 & 104 & 101 & \multirow[b]{2}{*}{$1.8022^{n}$} & \multirow[b]{2}{*}{0.406119} \\
\hline Yesi & 67 & 30 & 6 & 2 & 14 & 6 & 2 & 3 & 26 & 34 & & \\
\hline \multicolumn{13}{|c|}{ Have Hypertemaice } \\
\hline No & 121 & 50 & 8 & 2 & 27 & 10 & 4 & 20 & 45 & 56 & \multirow[b]{2}{*}{$2.6793^{n}$} & \multirow[b]{2}{*}{0.261932} \\
\hline Yes & 186 & 69 & 9 & 3 & 45 & 31 & 7 & 22 & 85 & 79 & & \\
\hline \multicolumn{13}{|c|}{ Have Kidney Diocase } \\
\hline No & 240 & 87 & 16 & 5 & 53 & 38 & 9 & 32 & 107 & 101 & \multirow[b]{2}{*}{$2.2917^{k}$} & \multirow[b]{2}{*}{0.317949} \\
\hline Yes & 67 & 32 & 1 & 0 & 19 & 3 & 2 & 10 & 23 & 34 & & \\
\hline \multicolumn{13}{|c|}{ Have GUEsophagus Disease } \\
\hline No & 198 & 77 & 12 & 4 & 46 & 23 & 6 & 30 & 81 & 87 & \multirow[b]{2}{*}{$1.1535^{\wedge}$} & \multirow[b]{2}{*}{0.561716} \\
\hline Yes & 109 & 42 & 5 & 1 & 26 & 18 & 5 & 12 & 49 & 48 & & \\
\hline
\end{tabular}

TABLE 2: Habits and co-morbidities of the patients surveyed.

* does not include patients reporting no OTC analgesic use.

$\wedge$ calculated by logistic regression

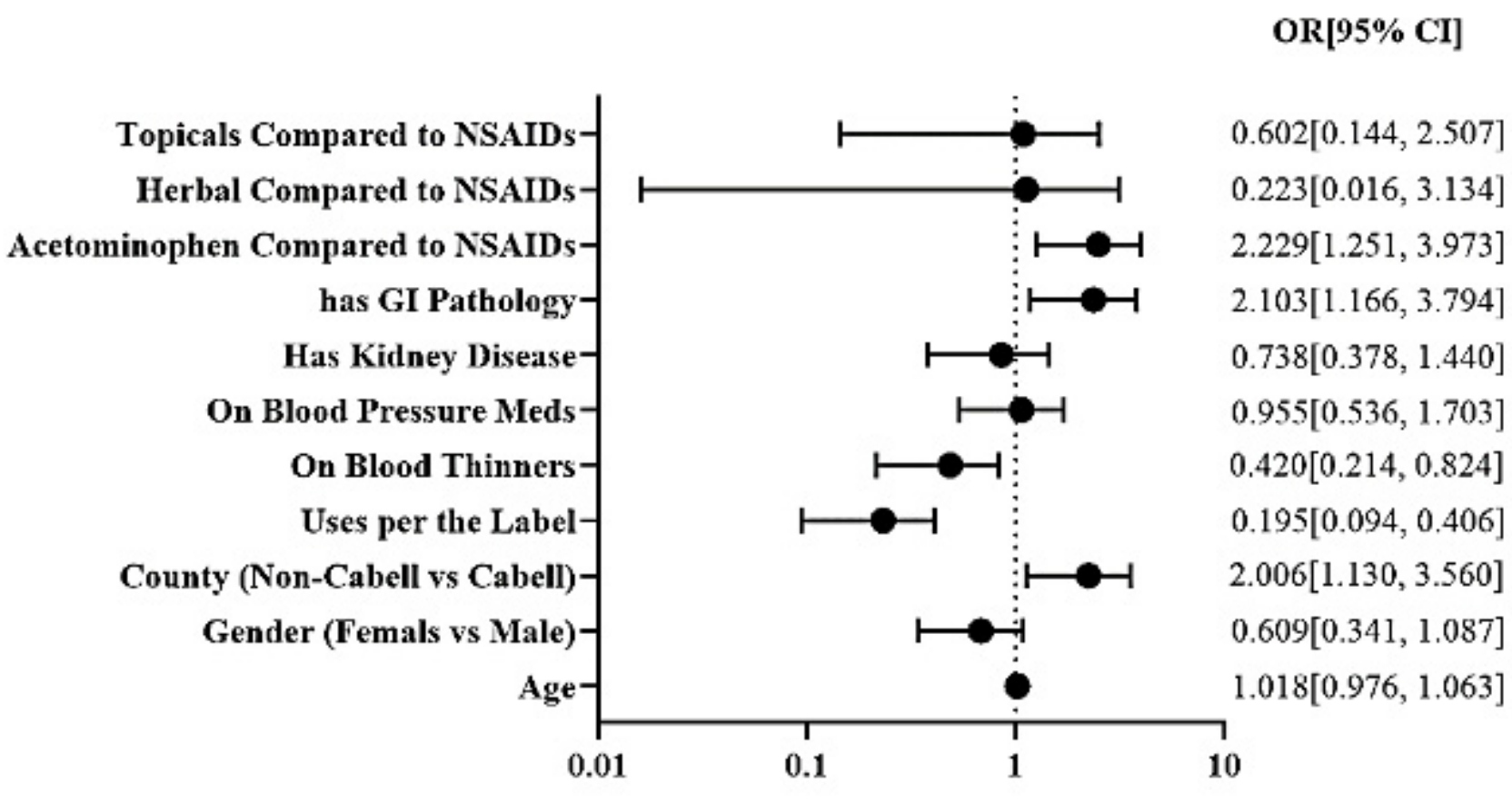

Highly Likely

Highly Unlikely

FIGURE 1: Factors affecting patients' likelihood of disclosing OTC medication use. 
to better understand this. Out of 307 participants, $265(86.3 \%)$ reported using OTC analgesics. The prevalence of their use should alert primary care physicians to ask all patients specifically about their OTC analgesic habits. Factors associated with an increased likelihood of informing their providers of OTC medication use were identified. Participants who followed labeled instructions and those on an anticoagulant were more likely to discuss OTC medications with their provider. Factors associated with a decreased likelihood of disclosing OTC medication use were residence outside of Cabell County, having Gl pathology, and the use of acetaminophen.

While these correlations are important to note, it is critical to understand the number of participants who take OTC medications with potential side effects related to their vulnerable chronic diseases. A well-known adverse effect of NSAID use is gastrointestinal ulcers, an increased risk for the older adult population..$^{3-7}$ Our study indicated that $30.6 \%$ of participants on NSAIDs with GI issues neither informed their provider about these medications nor followed medication instructions. This is significant for multiple reasons. The first concern is the relationship to the prescribing cascade. As patients begin taking an NSAID regularly or even over the recommended dose in the self-treatment of chronic pain, they can develop gastrointestinal ulcers and GI discomfort related to the NSAID. This leads to the prescription of medication for heartburn, which contributes to the already well-known problem of polypharmacy in our older adult patients. Secondly, nonselective NSAIDs contribute to ulcer formation by inhibiting prostaglandin synthesis and acting as an anti-platelet agent. ${ }^{7}$ This combination leads to increased bleeding risk in a vulnerable population.

It is also essential to assess for the use of NSAIDs with a prescribed anticoagulant. These anticoagulants such as warfarin, apixaban, dabigatran, enoxaparin, and heparin are all listed as Category D with recommendations to consider therapy modification due to increased risk of bleeding. ${ }^{8}$ Of this patient population, twenty-six admitted to using blood thinner with NSAIDs, and five (19.2\%) of those did not inform their provider and did not take them according to instructions (Table 3). Again, by acting as an anti-platelet agent, the risk of significant bleeding in patients taking prescription anticoagulants is greater. Therefore, it is important to instruct patients on the avoidance of OTC NSAIDs.

Finally, chronic diseases such as CKD and hypertension (HTN) can worsen with the use of NSAIDs. ${ }^{3,47}$ Twenty-three of the participants told by their doctor that they have CKD also took unmonitored NSAIDs. Approximately one-third of those who have CKD and use NSAIDs did not tell their doctor and did not use the medication according to instructions. Eighty-five of the participants have a diagnosis of HTN and use NSAIDs. Approximately one-fifth of those who have HTN and use NSAIDs neither told their doctor about their use nor used the medication according to instructions. NSAIDs should be avoided in CKD, which is more prevalent in the older adult population due to natural decline with age. It is also recommended that NSAIDs be avoided in those with HTN as they can cause an increase in blood pressure. ${ }^{7}$ Providers should be vigilant when discussing medication usage in those with CKD and HTN as these adverse events are more likely to lead to irreversible damage in the older adult population.

Based on the information gathered in this older adult Appalachian population, it is clear that OTC use is not always known to providers. OTC medications are not benign treatments in the general population and are even less so in this population. Providers need to review even brief use of OTC medications and ask specifically about OTC medications when providing care to their patients. It may also be beneficial to educate patients with chronic diseases about the safe use of OTC medication so that they have options when mild analgesia occurs.

The primary limitation of this paper is the inability to verify the medical information on the surveys from within the medical record. The impact of this is a potential underestimation of the prevalence of the queried pathologies within the studied population. This underreporting could be further exacerbated by the potential memory issues common in this population. While it appears that unmonitored use of OTC NSAIDs poses potential risks, patients' knowledge of those risks and methods of minimizing them should be better defined by additional research. 
As concerning as the NSAID results are, they show that community-dwelling, Appalachian older adults are even less likely to inform their physicians that they are taking acetaminophen. This has its own deleterious potential effects on health. Another avenue for future research would be to conduct a similar population analysis and pair it with medical conditions that acetaminophen impacts.

\section{CONCLUSION}

Most community-dwelling, Appalachian older adults utilize OTC analgesics for their chronic pain. Most of these patients, many of whom have a significant medical comorbidity burden, do not inform their physicians about their use of these medications. This study has identified a sizable percentage of this population with the potentially dangerous triad of unmonitored NSAID use, lack of adherence to OTC NSAID product labeling, and comorbidities adversely affected by NSAIDs. Further efforts need to be explored in order to protect this vulnerable population.

\section{AUTHOR AFFILIATIONS}

1. Department of Family and Community Health, Marshall University Joan C. Edwards School of Medicine, Huntington, West Virginia

\section{REFERENCES}

1. Ortman JM, Velkoff VA, Hogan $\mathrm{H}$. An aging nation: The older population in the United States. 2014 [cited 2021 Mar 2]; Available from: https://www. census.gov/library/publications/2014/demo/p251140.html

2. Lego B, Christiadi, Deskins J. Population Trends in West Virginia through 2030. 2014 [cited 2021 Mar 2]; Available from: https://researchrepository. wvu.edu/bureau be/37/

3. Harirforoosh S, Asghar W, Jamali F. Adverse effects of nonsteroidal antiinflammatory drugs: an update of gastrointestinal, cardiovascular and renal complications. J Pharm Pharm Sci. 2013;16(5):821-47. PubMed PMID: 24393558.

4. Phillips AC, Polisson RP, Simon LS. NSAIDs and the elderly: Toxicity and economic implications. Drugs Aging. 1997;10(2):1 19-30. PubMed PMID: 9061269.

5. Roumie CL, Griffin MR. Over-the-counter analgesics in older adults: A call for improved labelling and consumer education. Drugs Aging. 2004;21(8):485-98. PubMed PMID: 15182214.

6. O'Neil CK, Hanlon JT, Marcum ZA. Adverse effects of analgesics commonly used by older adults with osteoarthritis: focus on non-opioid and opioid analgesics. Am J Geriatr Pharmacother. 2012;10(6):331-42. PubMed PMID: 23036838.

7. Risser A, Donovan D, Heintzman J, Page T. NSAID prescribing precautions. Am Fam Physician. 2009;80(12):1371-8. PubMed PMID: 20000300.

8. Rochon MD MPH FRCPC P. Drugs \& Drug Interaction [Internet]. Uptodate.com. [cited 2021 Mar 2]. Available from: https://www.uptodate. com/contents/drug-prescribing-for-older-adults

9. Marcum ZA, Duncan NA, Makris UE. Pharmacotherapies in Geriatric Chronic Pain Management. Clin Geriatr Med. 2016;32(4):70524. PubMed PMID: 27741965.

10. Ali A, Arif AW, Bhan C, Kumar D, Malik MB, Sayyed $Z$, et al. Managing chronic pain in the elderly: An overview of the recent therapeutic advancements. Cureus. 2018;10(9):e3293. PubMed PMID: 30443463.

11. Wolf MS, King J, Jacobson K, Di Francesco L, Bailey SC, Mullen R, et al. Risk of unintentional overdose with non-prescription acetaminophen products. J Gen Intern Med. 2012;27(12):1587-93. PubMed PMID: 22638604.

12. Yoon E, Babar A, Choudhary M, Kutner M, Pyrsopoulos N. Acetaminophen-induced hepatotoxicity: A comprehensive update. J Clin Transl Hepatol. 2016;4(2):131-42. PubMed PMID: 27350943.

13. Dahlhamer J, Lucas J, Zelaya C, Nahin R, Mackey $\mathrm{S}, \mathrm{DeBar} \mathrm{L}$, et al. Prevalence of chronic pain and high-impact chronic pain among adults - United States, 2016. MMWR Morb Mortal Wkly Rep. 2018;67(36):1001-6. PubMed PMID: 30212442.

14. Barat I, Andreasen F, Damsgaard EM. The consumption of drugs by 75-year-old individuals living in their own homes. Eur J Clin Pharmacol. 2000;56(6-7):501-9. PubMed PMID: 11049014.

15. Stoehr GP, Ganguli M, Seaberg EC, Echement DA, Belle $S$. Over-the-counter medication use in an older rural community: the MoVIES Project. J Am 
Geriatr Soc. 1997;45(2):158-65. PubMed PMID: 9033513.

16. Schmiedl S, Rottenkolber M, Hasford J, Rottenkolber D, Farker K, Drewelow B, et al. Selfmedication with over-the-counter and prescribed drugs causing adverse-drug-reaction-related hospital admissions: results of a prospective, long-term multi-centre study. Drug Saf. 2014;37(4):225-35. PubMed PMID: 24550104.

17. Qato DM, Alexander GC, Conti RM, Johnson $M$, Schumm P, Lindau ST. Use of prescription and over-the-counter medications and dietary supplements among older adults in the United States. JAMA. 2008;300(24):2867-78. PubMed PMID: 19109115. 